\title{
Tiếp biến văn hóa tại Việt Nam đầu thế kỉ 20: "Nơi tầng 2 - Phố Phái"
}

Theo sc.sshpa.com 28/01/2019 09:54

Trong quãng thời gian nhàn rỗi, họa sĩ Bùi Xuân Phái trò chuyện với bạn bè ở quán café Lâm, nơi ông tìm cảm hứng sáng tác về Hà Nội. Là người Hà Nội gốc, họa sỹ gắn bó với khu phố cổ từ nhỏ.

Sự tự tại trong nhàn rỗi giúp ông "đọc" những vẻ đẹp lạ lùng ở các ngôi nhà từ thời Nguyễn, mái thì võng xuống, hai đầu hồi lồi ra, nhà cửa thì xiêu vẹo. Bắt đâu là vẽ dựa trên mẫu nhà thật, nhưng sau đó, Bùi Xuân Phái đã sử dụng hình ảnh đọng lại trong suy tư để vẽ. Vì thế, tranh phố Hà Nội của Bùi Xuân Phái luôn chất chứa vẻ đẹp đặc biệt của ngẫm ngợi, hoài niệm dù ông rất kiệm màu, và các nét vẽ không quá phô trương. Sau này, nhà văn Nguyễn Tuân đã chơi chữ Phái Phố, hay Phố Phái từ tên cổ của Hội An là "Phai Phô" để gọi tranh của Bùi Xuân Phái, lâu dần nó trở thành một ý niệm (hay "nhân hiệu") vang danh nơi nơi.

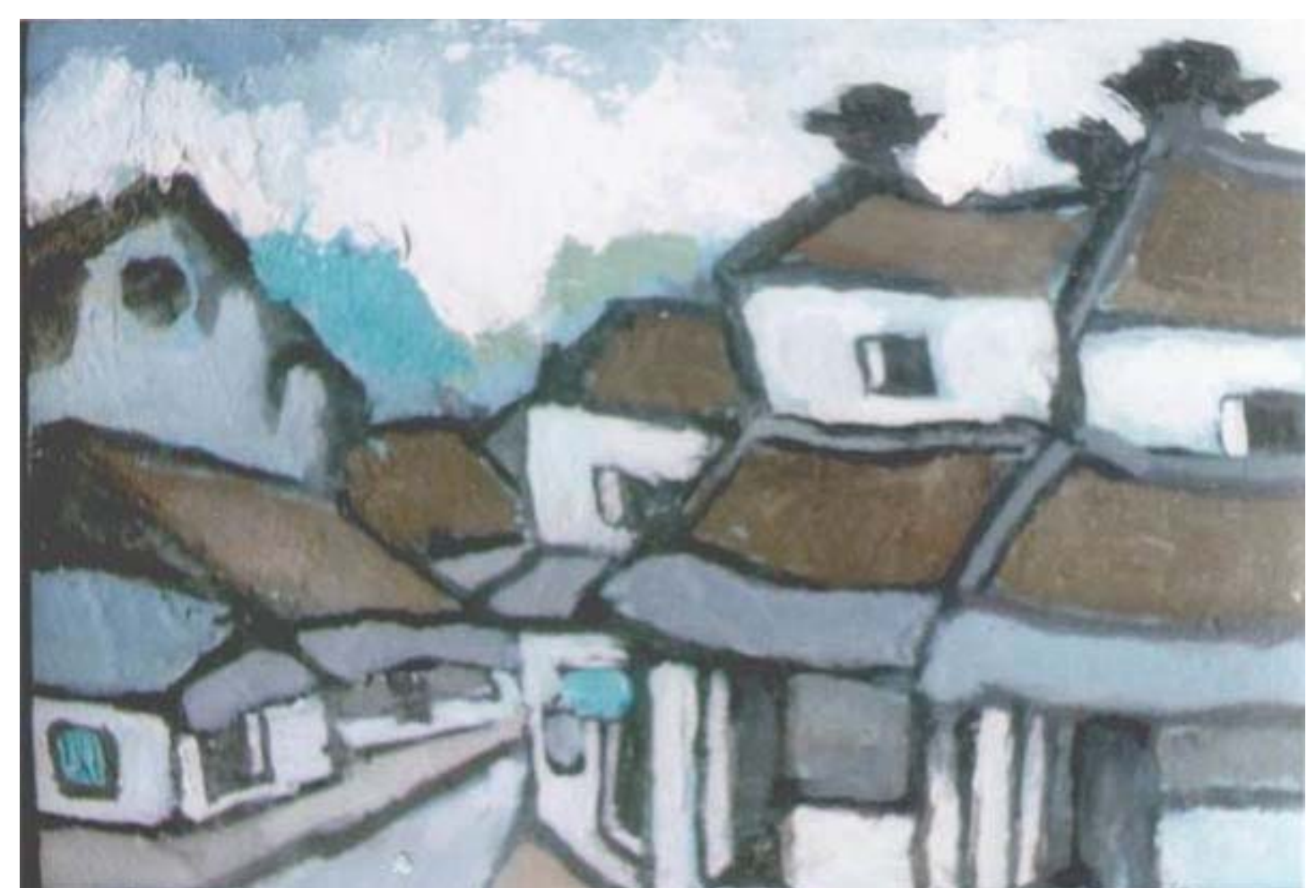




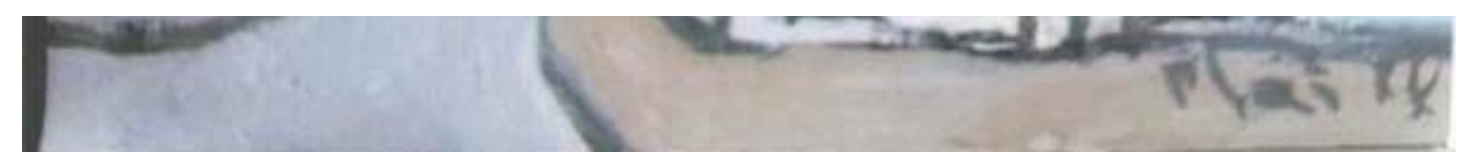

(Nguî̀n: WikiArt)

Chất hoài niệm toát ra từ những con phố Hà Nội trong tranh của Bùi Xuân Phái khó mà cắt nghĩa hết được. Tại sao hình dáng ây, chi tiết ây lại gợi lên cảm xúc mãnh liệt như vậy? Thậm chí, vẻ đẹp và sự bí ẩn của Phố Pháicòn khiến các vị khách phương xa khát khao, xao xuyến.

Hà Nội những ngày giáp Tết, con đường hàng ngày chật chội hơn vì chợ hoa đào tràn ngập. Quanh khu phố cổ thì đông nghìn nghịt người qua lại mua sắm, dạo chơi. Các cửa hàng trên phố trang trí ngợp một màu đỏ của Tết, của hoa đào, của câu đối đỏ, của phong bao lì xì. Thế nhưng, cái cổ kính của phố Hà Nội bị lọt thỏm giữa một rừng đỏ nhộn nhịp ấy. Phải hơi nghển cổ lên một chút, chau mày tìm kĩ, thì mới thấy rõ một thế giới khácđang im lìm vẫn nằm giữa Hà Nội cứ mỗi ngày lại mới thêm một chút.

Thế giới đó nằm ở tầng 2 những ngôi nhà trên phố cổ, nơi chưa bị những gian hàng trưng bày hay những cánh cửa kính hiện đại thay thế. Có những nhà được thay mới lớp sơn, nhưng những dáng hình, chi tiết chạm trổ, hay cách thiết kễ vẫn toát lên sự quen thuộc đã cả một thế kỉ. Hóa ra Phố Phái, dù không còn toàn vẹn, là ở đây.

Nhờ quá trình quan sát và lưu giữ lại thế giới trầm lắng ây, một nghiên cứu mới đã xuất hiện trong những ngày giáp Tết Kỷ Hợi 2019. Cultural evolution in Vietnam's early 20th century: a Bayesian networks analysis of Franco-Chinese house designs (Tạm dịch: Tiếp biến văn hóa tại Việt Nam đầu thế kỉ 20: Phân tích phong cách thiết kế nhà kiểu Pháp - Trung bằng phương pháp lưới Bayesian) được hoàn thiện ngày 26 tháng 1 vừa qua, hiện được đăng tải dưới dạng bản thảo trên các hệ thống OSF, SocArxiv, vàSSRN.

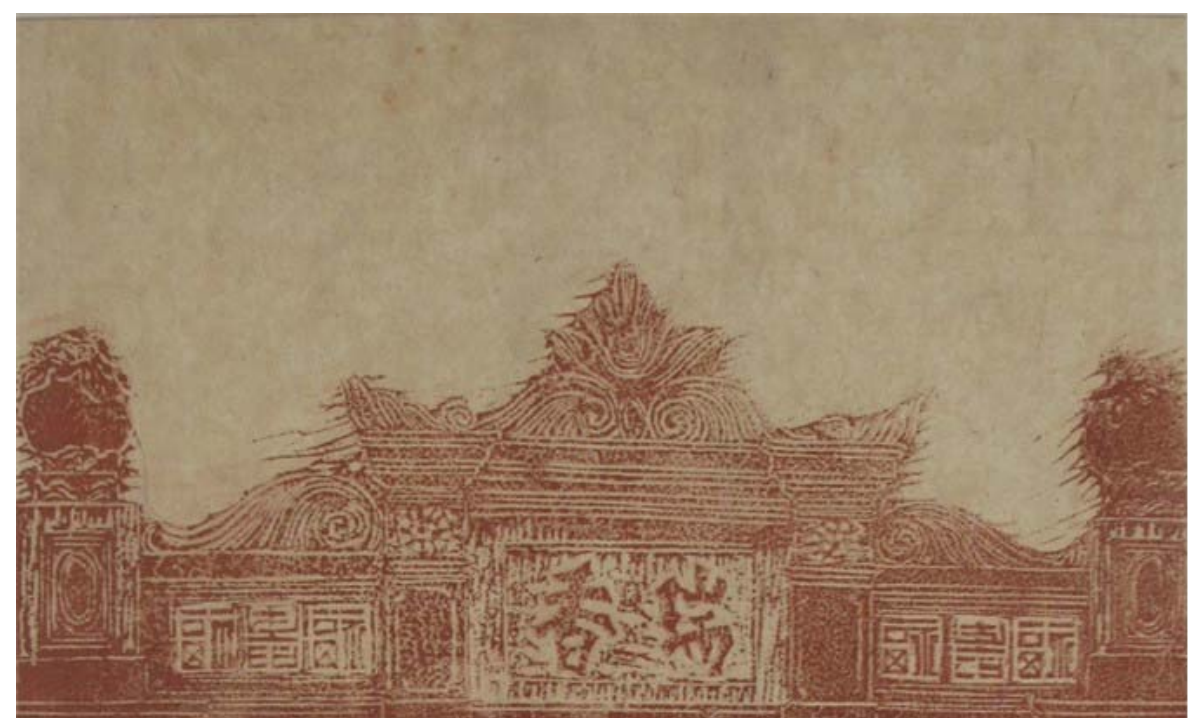




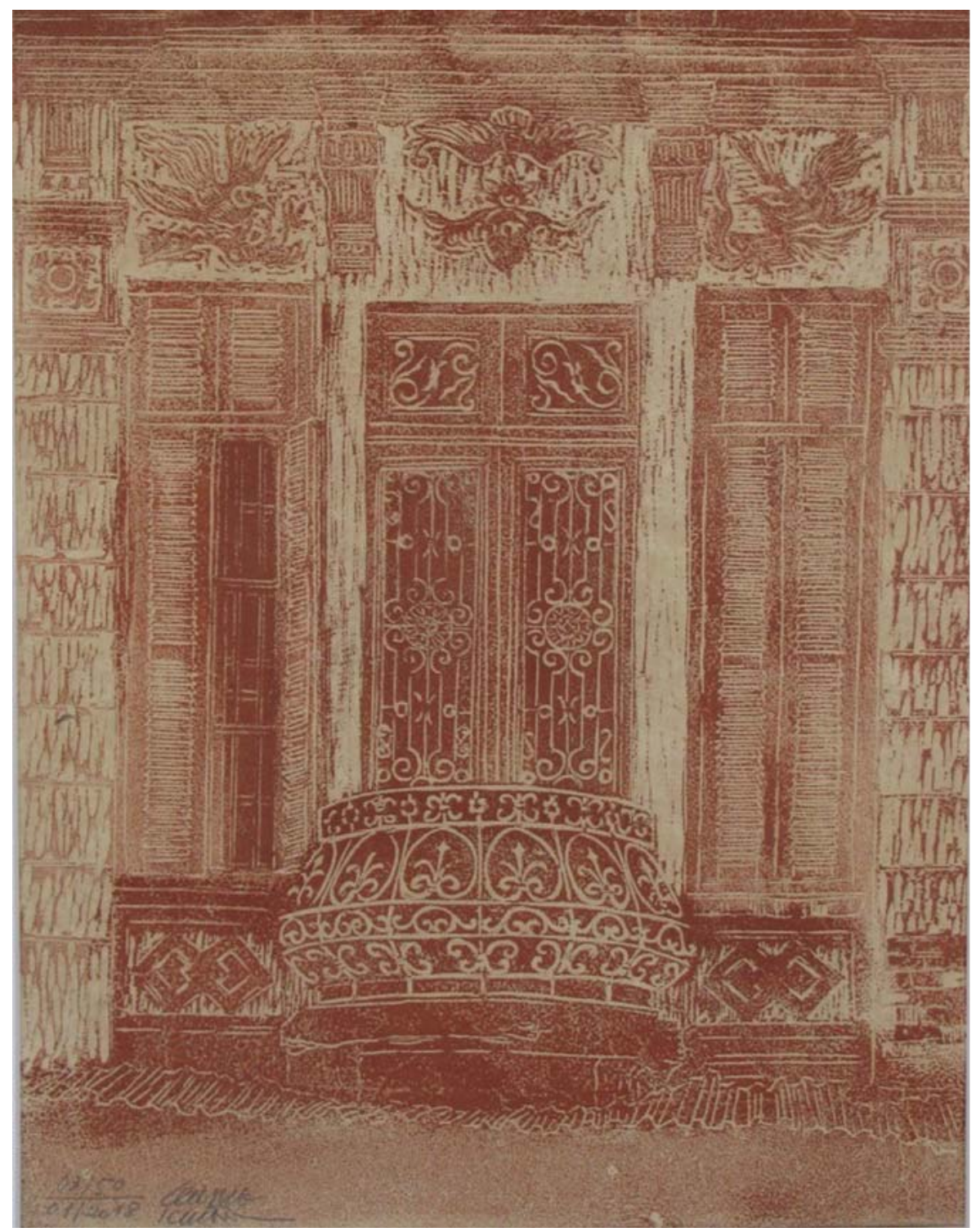

(@2018 Bui Quang Khiem)

Ngôi nhà mang một ý nghĩa to lớn với mỗi người Việt Nam. Những ngày Tết, yếu tố này lại càng rõ nét hơn khi mọi người nô nức về quê ăn tết, cố gắng sum họp bên gia đình dù công việc bận rộn thế nào. Ngôi nhà là hiện thân của những giá trị gia đình, là tài sản lớn không chỉ của một người mà của nhiều thế hệ. Khi các giá trị Tam giáo, đặc biệt là Khổng giáo, ăn sâu vào đời sống gia đình Việt Nam, việc xây nhà, thiết kế không gian trong nhà của mỗi gia đình vì thế cũng không đơn thuần chỉ là câu chuyện về kiến trúc, mà còn là quan niệm, niềm tin của các thế hệ trong gia đình gửi gắm vào trong đó. Thời kì đầu thế kỉ 20là thời điểm Việt Nam còn nhập nhằng giữa cái gốc văn hóa Tam giáo, Trung Quốc và sự ảnh hưởng của người Pháp. Vì thế, những ngôi nhà xây dựng trong thời gian này trở thành nơi chất chứa tâm hồn Việt giằng xé giữa hai hệ giá trị: những người già học đạo Nho và những người trẻ học phong cách Pháp.

Sử dụng ảnh chụp mặt tiền của 68 ngôi nhà cổ tại Hà Nội, nhóm nghiên cứu đã dữ liệu 
hóa các chi tiết đặc trưng có thể báo hiệu quá trình tiếp biến văn hóa mới bắt đầu, đang diễn ra, hay đã hoàn tất. Sau đó, dữ liệu được phân tích bằng phương pháp lưới Bayesian để trả lời hai câu hỏi:

1. Liệu có thể dựa trên cảm quan về thẩm mỹ, kiến trúc và thiết kế của các ngôi nhà này để tìm kiếm dấu tích của quá trình tiếp biến văn hóa ở đâu thế kỉ 20 tại Việt Nam hay không?

2. Yếu tố nào có ảnh hưởng lớn nhất đến cảm nhận về quá trình tiếp biến văn hóa của những người Việt Nam, vốn được tiếp xúc với những thiết kế kiến trúc và hành vi văn hóa này thường xuyên?

Trước hết, nghiên cứu đã cho thấy các nghiên cứu nhân văn hoàn toàn có thể tận dụng các phương pháp kĩ thuật thống kê hiện đại. Nghiên cứu sử dụng một lượng dữ liệu không quá lớn, thiết kế các biến có tính đại diện cao, và áp dụng kĩ thuật mạnh mẽ của phương pháp lưới Bayesian, tận dụng cả hai cách tiếp cận tần suất (frequentist) và Hamiltonian Markov chain Monte Carlo (MCMC), để cho thấy khả năng phát hiện quá trình tiếp biến văn hóa chỉ dựa trên đánh giá cảm quan về thẩm mỹ, kiến trúc và thiết kế của mặt tiền các ngôi nhà cổ. Trước đó, một nghiên cứu công bố trên Palgrave Communications cũng đã cho thây công năng nhờ việc kết hợp dữ liệu từ truyện cổ tích và thống kê Bayesian để phát hiện ra hiện tượng: cộng tính văn hóa. Các nhà nghiên cứu hy vọng hướng đi mới này sẽ tiếp tục đóng góp thêm các phát hiện mới về văn hóa, nhân học, lịch sử.

Trả lời cho câu hỏi thứ hai, nghiên cứu đã chỉ ra sự ảnh hưởng mạnh mẽ của các yếu tố đạo Phật trên mặt tiền nhà tại Việt Nam. Những biểu tượng đặc trưng như hoa sen, hoa cúc, bánh xe luân hồi được các kiến trúc sư và/hoặc người thợ đưa vào mặt tiền của mỗi ngôi nhà một cách khéo léo. Dù không dễ dàng nhận ra, nhưng sự xuất hiện của các yếu tố đạo Phật khiếnphong cách trang trí của ngôi nhà đậm tính Trung Quốc, hoặc lai giữa Pháp và Trung Quốc. Phong cách trang trí lai cũng khiến xác suất của quá trình tiếp biến văn hóa đang diễn ra là cao nhất.

Các bức ảnh được chụp rải rác trong những buổi sáng sớm hoặc trong ngày Tết thưa thớt người lại đặt ra những câu hỏi lớn về quá trình tiếp biến văn hóa tại Việt Nam. Dường như, quá trình đó vẫn đóng băng trên tầng 2 những ngôi nhà cổ may mắn còn giữ được nguyên vẹn. Một số ngôi nhà đã quá cũ thì đang dần bị dõ bỏ, thậm chí, có ngôi nhà vốn là đình làng cũng sẽ sớm trở thành một siêu thị nào đó.

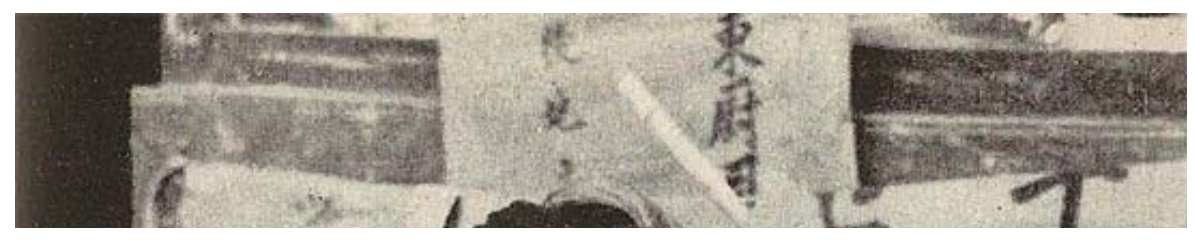




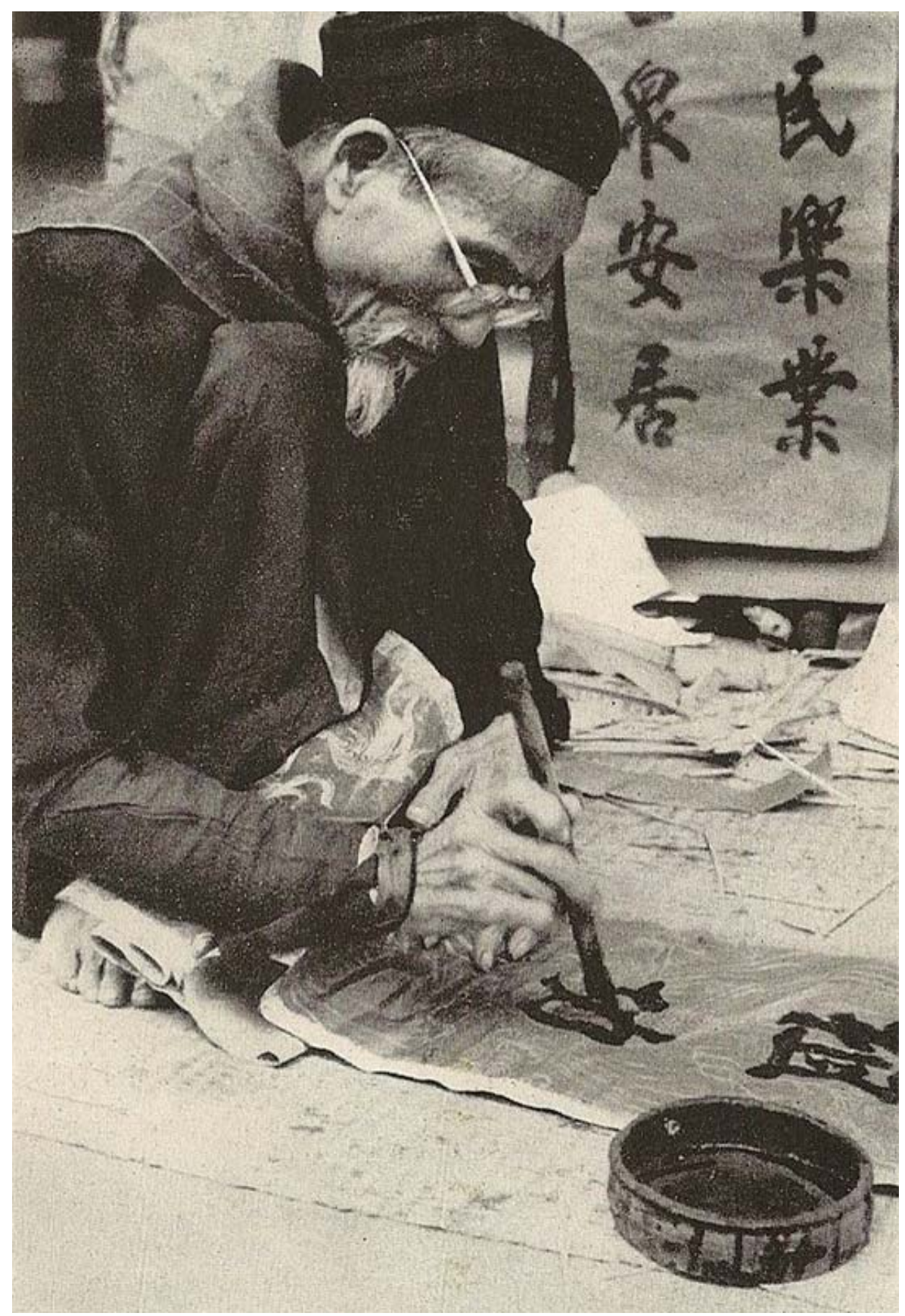

(A Calligraphist in Vietnam from Wikimedia)

Nhắc đến những thứ tưởng như sẽ sớmmất đi, nhà thơ Vũ Đình Liêntừng viết:

Nhưng mỗi năm mỗi vắng

Người thuê viết nay đâu?

Giấy đỏ buồn không thắm

Mực đọng trong nghiên sầu.

(Vũ Đình Liên, 1936)
But fewer buyers came each year

Admirers, where did they go...?

Unused ink laid like black tears.

Red paper dulled in sorrow...

(Translated by Vuong Thu Trang, 2011) 
Khổ thơ trích từ bàiông Đồ (1936) nổi tiếng, với nhiều bản dịch sangtiếng Anh được tác giả Phạm Trọng Lệ tổng hợp lại trong nghiên cứu của mình về ý nghĩa của Tết với người Việt. Những ông đồ viết mực Tàu giấy đỏ trong những năm tháng khó khăn cứ lay lắt không biết còn có thể tồn tại, nhất là khi chữ Hán được thay thế bởi chữ Quốc ngữ. Ngày nay, hàng năm mọi người lại đến thăm Văn Miếu, người thì xin chữ Học (學) với mong muốn đỗ đạt, người thì xin chữ Lộc (禄) để mong năm tới làm ăn thuận lợi. Một nét văn hóa của người Việt Nam may mắn được tiếp tục sống giữa hiện tại.

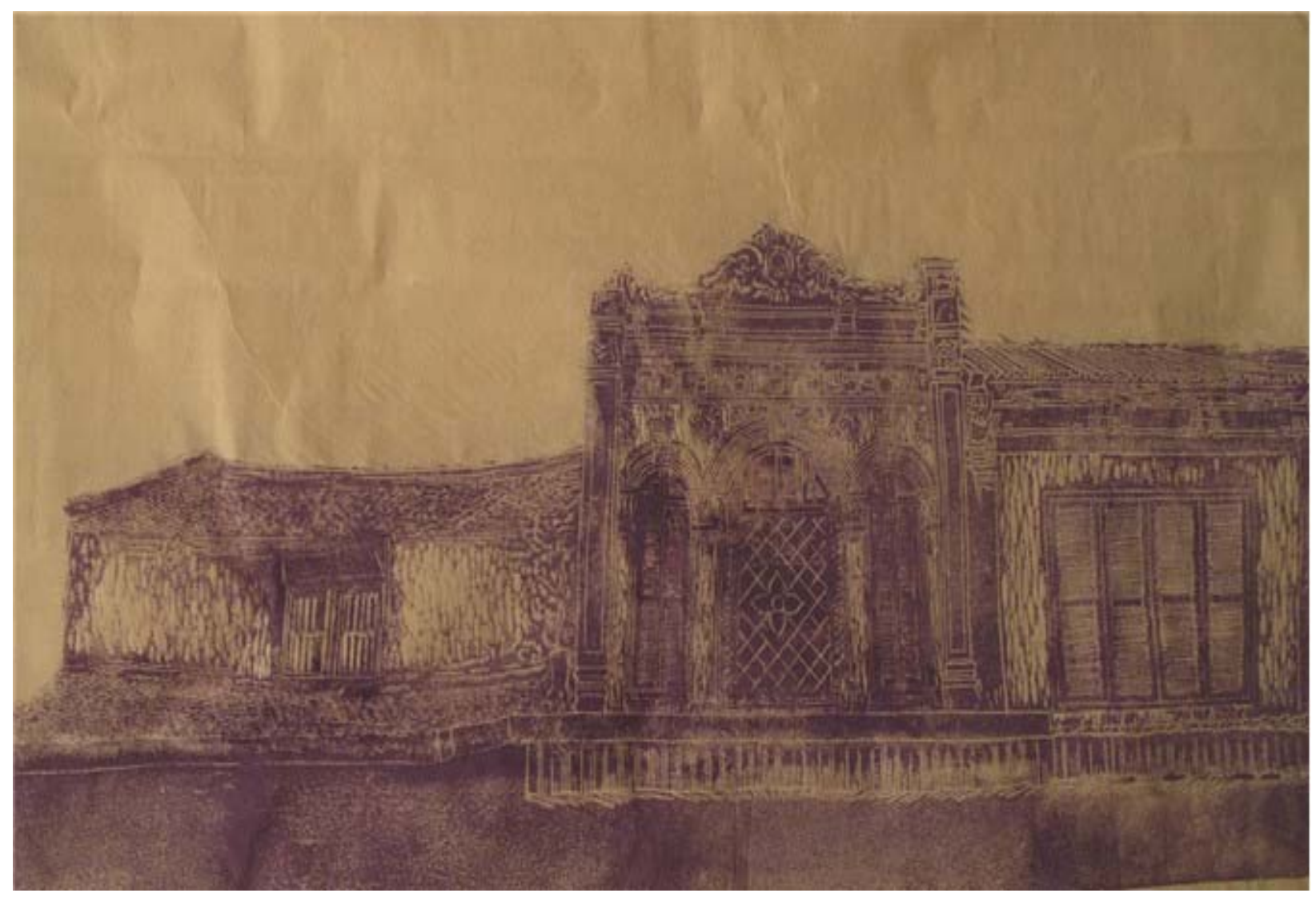

(C2016 Bui Quang Khiem)

Thế nhưng, khi những ngôi biệt thự, chung cư mớithay nhau mọc lên và thay thế các ngôi nhà cổ cũ kĩ kia, liệu chúng sẽ còn có thể ở đấy mãi? Vì thế, vẻ đẹp lớn nhất của những bức ảnh, tranh vẽ, bộ dữ liệu, và nghiên cứu này, chính là ở cách các nhà khoa học viết về một thế giới dần biến mất.

*Tham khảo:

Vuong, Q., Khiem, B. Q., La, V., Vuong, T., Ho, T. M., Nguyen, H. T., ... Ho, T. (2019, January 26). Cultural evolution in Vietnam's early 20th century: a Bayesian networks analysis of Franco-Chinese house designs. SocArXiv. DOI:10.31235/osf.io/7p9zf. URL:https://osf.io/preprints/socarxiv/7p9zf/download 
Pham, T. L. (2018). The meaning of Tết in Việt Nam. The Firmament Literacy Journal, $10(4), 8-18$.

Vuong, Q.H., Ho, M.T., Vuong, T.T., Tran, K., \& Ho, M. (2018b). "Paintings can be forged, but not feeling": Vietnamese art-Market, fraud, and value. Arts, 7(4), 62, doi: $10.3390 /$ arts 7040062 .

Vuong Q.H., La V.P., Vuong T.T., Nguyen V.H., Ho M.T., Nguyen T.H.K., Bui Q.K., Ho M.T. (2018). Cultural additivity: Behavioural insights from the interaction of Confucianism, Buddhism, and Taoism in folktales. Palgrave Communications, 4, DOI: 10.1057/s41599-018-0189-2. URL: https://www.nature.com/articles /s41599-018-0189-2.

Nguồn: 